\title{
THE EXCRETION OF GONADOTROPHIC HORMONE BY PREPUBERAL AND ADOLESCENT GIRLS
}

\author{
By H. R. CATCHPOLE AND W. W. GREULICH \\ (From the Adolescence Study Unit and the Departments of Physiology and \\ Anatomy, Yale University School of Medicine; New Haven)
}

(Received for publication January 4, 1943)

We have recently summarized the literature on gonadotrophin excretion in both male and female children, and have reported in detail our own findings in adolescent boys (1). In brief, hormone cannot be detected in boys much before the 13th year; thereafter, its amount may be correlated with increase in chronological age, and, perhaps to a greater extent, with advancing developmental status. Studies relating to the hormonal aspects of the attainment of sexual maturity in the female are meager in number and results. On the basis of our own work (2), and that of Nathanson and co-workers (3), it appeared that in girls, hormone could be detected somewhat earlier than in boys, but that the general level of excretion in immature subjects of both sexes was undoubtedly low. From such levels, hormonal excretion in the female presumably advances during adolescence to adult values which eventually fall into a cyclic pattern.

Gonadotrophin excretion in the adult female has been studied by serial assays throughout the menstrual cycle. Levin (4), in one subject, found less than $7.5 \mathrm{M}$. U. U. ${ }^{1}$ to be excreted except at 2 points; these were days 12 and 13 which showed $35 \mathrm{M}$. U. U., and days 20 and 21 which showed $10 \mathrm{M}$. U. U. per 24 hours. His second subject showed less than 7.5 M. U. U. for the first 22 days of the cycle, except for a peak of $15 \mathrm{M}$. U. U. on the 13th and 14th days. Werner (5) described somewhat similar cycles in 5 subjects; relatively constant amounts during the bulk of the cycle were replaced by peaks of from 15 to $80 \mathrm{M}$. U. U. at times varying from the 10th to the 18th days of the cycle. Main peaks were occasionally preceded by subsidiary peaks. von Haam and Rothermich (6) found from 1 to 3 peaks of "prolan" excretion during the cycle. The maximal amounts found were $30 \mathrm{M}$. U. U. per 24 hours (in 1 case,

\footnotetext{
1 M. U. U. refers to mouse uterine units of gonadotrophin.
}

50 M. U. U.) while the basal level was from 0 to $10 \mathrm{M}$. U. U. D'Amour (7), in 25 out of 29 cycles, found peaks of from 4 to 16 International Units (probably 40 to $160 \mathrm{M}$. U. U.) between the 12 th and 16 th days, and in the remaining 4 cycles, no evidence of peaks. In the "active" cycles, there was evidence of supplementary activity at times other than the period of mid-interval.

These results indicate the end-result of the process of maturation in females, as it affects the behavior of pituitary gonadotrophin, and findings in subjects of younger age must be viewed with these in perspective. With a wide range of excretion as shown in the adult, it is clear that single specimens may represent very imperfectly the hormonal status of the individual. With this possibility in mind, our studies describe serial observations only.

\section{METHODS AND MATERIALS}

The method used for hormone extraction and assay was the same as that used for the investigation of gonado-

TABLE I

List of 12 subjects showing age at assay, age at first menses, and percentage of days upon which positive hormonal excretion was recorded

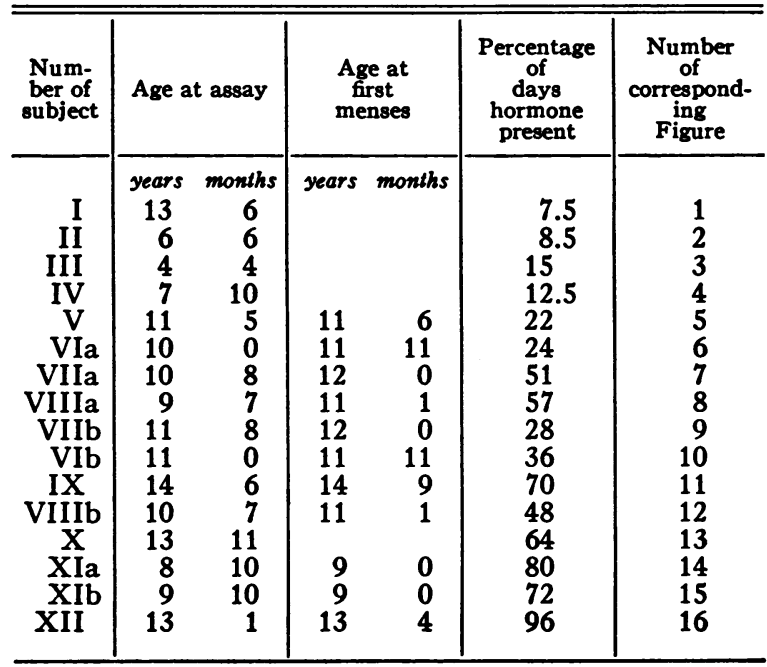


4

M.U.U.

No. 1

$A G E \quad 13.6$

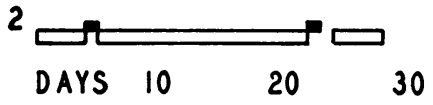

FIg. 1

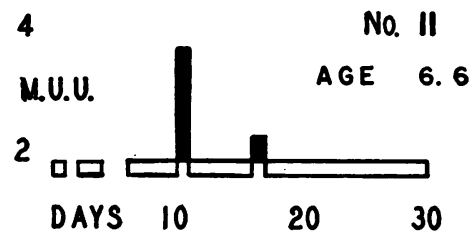

Fig. 2

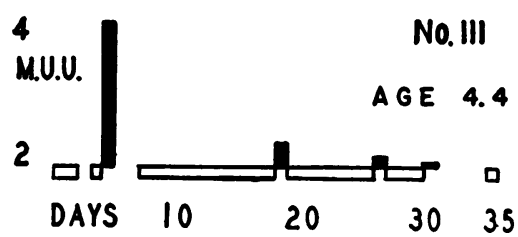

FIG. 3

No. IV

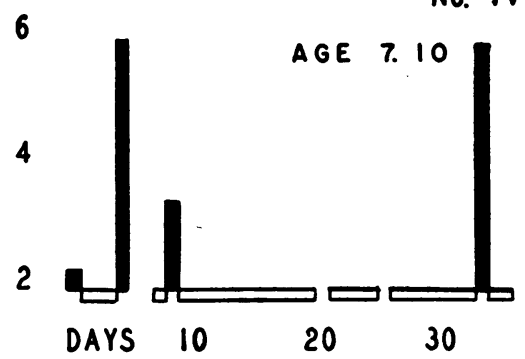

Frg. 4

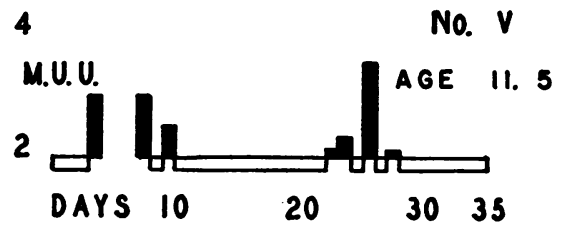

Fig. 5

trophin excretion in boys (1). The subjects were 4 girls residing at a correctional institution (Nos. I, IX, X, XII), and 8 girls representing ambulatory cases from a tuberculosis sanitorium (Nos. II to VIII ; No. XI). Studies on 4 of the latter (Nos. VI, VII, VIII, XI) were repeated after a 1-year lapse of time. An attempt was made to obtain daily 24-hour urine specimens from all subjects for a period of 1 month at least, and, with certain unavoidable gaps, this was accomplished. This report covers
16 series of gonadotropin determinations, each lasting 1 month. The limitations of the assay method have been previously discussed (2). Since one of our main problems was to establish the presence or absence of minimal amounts of hormone, we frequently tested for very small amounts and depended upon a dose-response curve to estimate the titer of specimens that proved to be more active. In addition to the results reported, a fairly large series of extractions were made during the summer of 1939; many of these extracts were highly toxic to the test animals, and it was decided to discard the whole

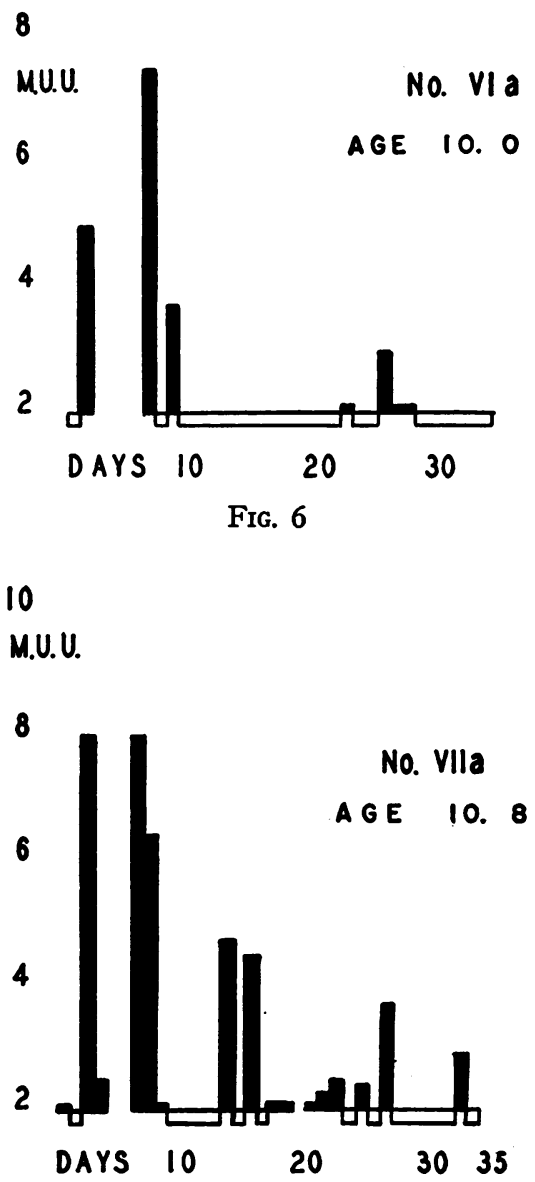

Fic. 7

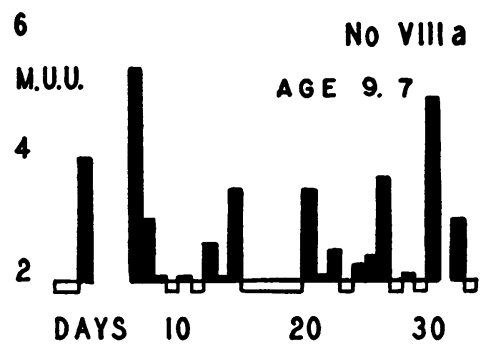

Frg. 8 
series. In general, the method we used yielded non-toxic preparations. The subjects ranged in age from 4 years and 4 months to 14 years and 6 months. Only 1 had menstruated before the assays were made, thus the group was a pre-menarchial one. Several of the subjects ex- perienced first menses from one to several months after the determinations were performed. In 3 of the youngest girls, menses would not have been expected to occur for several years, and in 2 of the older girls, the onset of menses presumably occurred some time after completion of this work, and the actual dates could not be secured. Table I lists the subjects, and records the ages at which the assays were performed and at first menses. For convenience, they are listed in the same order as their charts appear in Figures 1 to 16 . Also given is the percentage of days on which a positive hormonal excretion (whatever its value) was recorded. For subjects VI, VII, VIII, and XI, the 2 series of determinations made are represented by the suffices $a$ and $b$.

\section{RESULTS}

Figures 1 to 16 show the daily excretions of gonadotrophic hormones for the 12 subjects, ex-

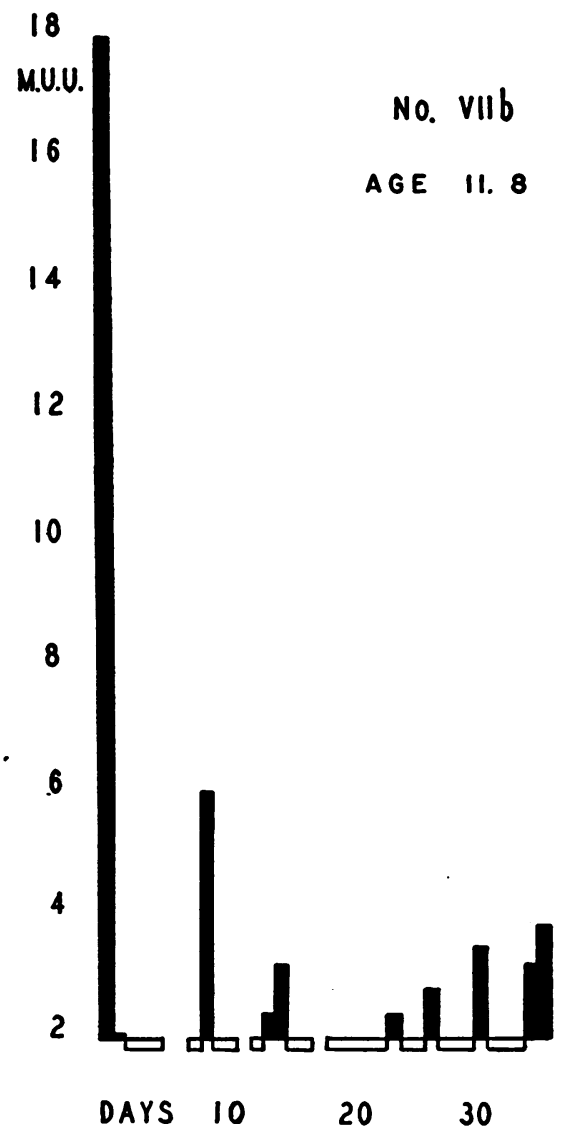

FIG. 9

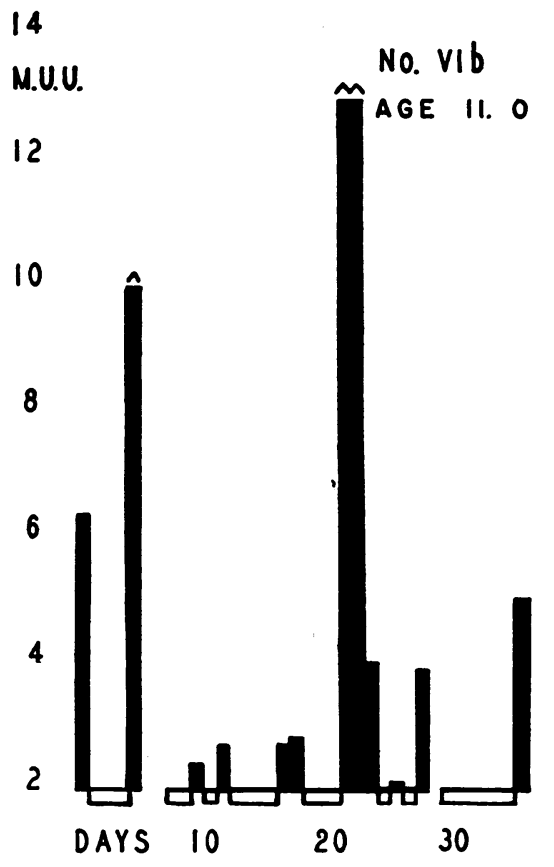

Fig. 10

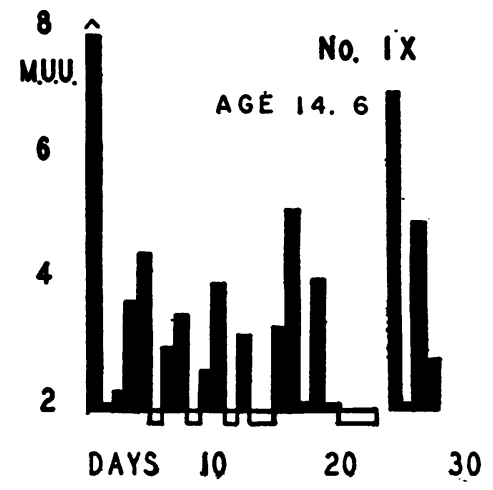

FIG. 11

pressed in mouse uterine units. These records have been arranged in an ascending series, beginning with those showing low or infrequent hormone excretion and extending up to those with higher or more frequent hormone excretion. This arrangement is to some extent arbitrary, since as the hormonal picture increases in complexity, certain tendencies become apparent which do not always parallel each other. These tendencies are: (1) an increase, as the series is ascended, in the proportion of days upon which a positive excretion of hormone is recorded; (2) an increase, in the same direction, in the average level of hor- 
12

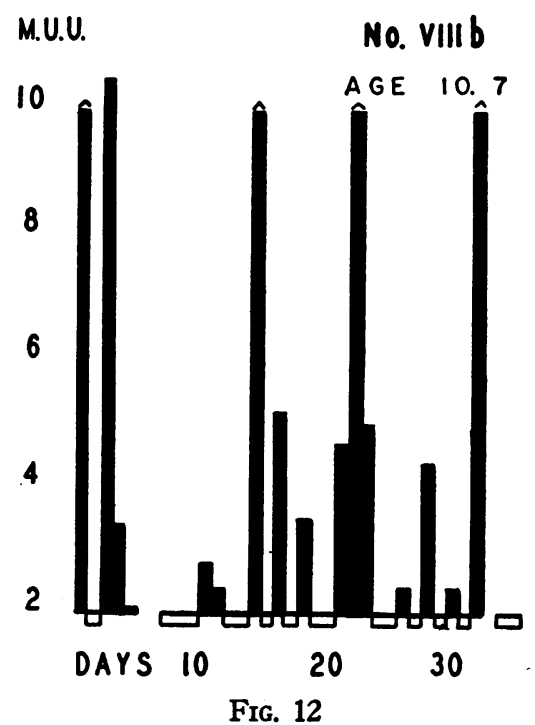

14

M.U.U.

12

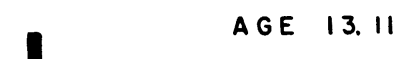

10

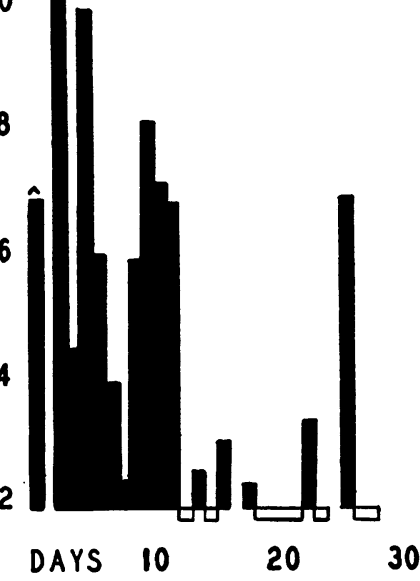

Fig. 13

amounts of hormone as low as 2 or 3 mouse units per 24 hours; this covers a range below that usually employed, and many of our positive findings would be described as "negative" in technics testing for 7.5 M. U. U., or more, per 24 hours. In the figures, the base-line has been drawn at 2 mouse units.

The 2 youngest girls in the series (Nos. II and III) showed a typically blank record, 55 assays yielding only 5 minimal positive values of between 2 and $4 \mathrm{M}$. U. U. In girls of 9 years or older, the hormonal picture tended to become more "advanced," in one or more of the ways described above. However, a subject of 13 years and 6 months (No. I) showed absolutely minimal or negative excretion over the entire 1 -month period studied. On the other hand, a girl of 8 years and 10 months (No. XI) showed a surprisingly active

mone excreted; (3) a more irregular tendency for large amounts of hormone to be excreted on individual days. It will be seen from Table I that the arrangement selected attempts to effect a compromise between these tendencies, all of which may be held to indicate increasing hormonal activity.

The assay method used permitted testing for

20

M.U.U.

No. XI a

$A G E$ 8. 10

18

16

14

12

10

8

6

\section{0}

M.U.

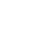

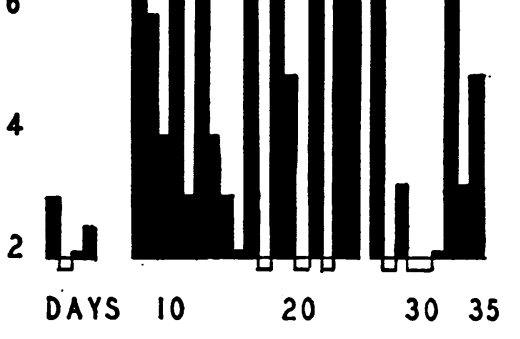

Fig. 14 
12

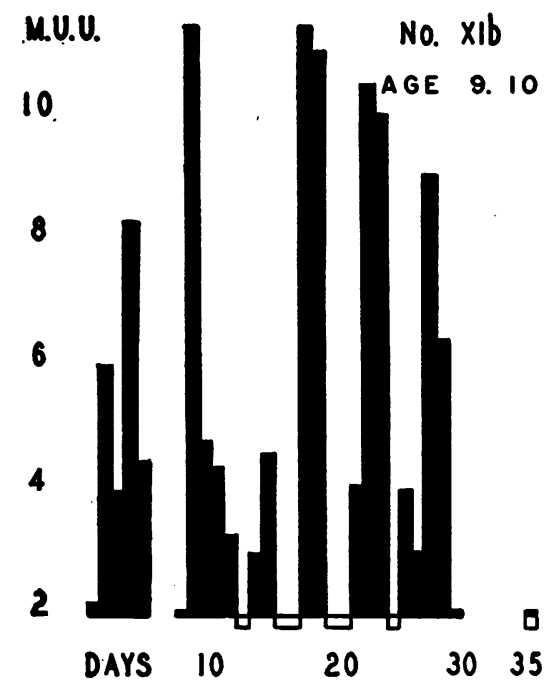

FIg. 15
14

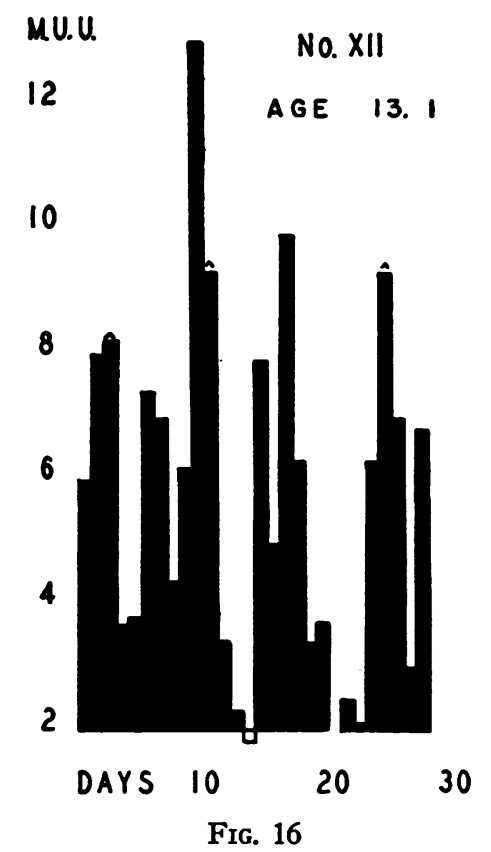

Fig. 16 hormonal pattern; 2 months after completion of the determinations, this subject vindicated the record by experiencing first menses. Hormonal behavior appeared to be related to the proximity of menses; subjects Nos. VI, VII, VIII, IX, and XII menstruated from 2 to 11 months after periods during which hormonal activity had been shown to be marked. But this relationship is not an invariable one, since subject No. $\mathrm{V}$ menstruated 1 month after a distinctly inactive type of hormone pattern had been shown.

The results of the repeat studies showed, in 2 subjects, a very striking progression in hormonal output in the space of a year (Nos. VI and VIII, $a$ and $b$ ). In one subject (No. VII, $a$ and $b$ ), the second record appeared to be in some respects less advanced than the first, except for an unusually high peak, shown on a single day in the later series. The remaining subject (No. XI, a and b) was the early maturing girl, previously mentioned, who showed an advanced type of hormonal excretion during each series of determinations.

\section{DISCUSSION}

It became apparent in performing this series of assays that the day to day variation in a given subject might be considerable. Some variation must inevitably be ascribed to factors involved in the technics of collection, extraction, and assay of the urinary preparations. With due allowance for this possibility of error, certain broad conclusions would seem to be deducible from the data.

The picture of pituitary gonadotrophic hormone excretion during the periods of pre-puberty and adolescence represents a stage between that condition of quiescence seen in early childhood, and that of the fully developed adult cycle. From the series of records obtained may be seen evidence of a definite progression. This progression is associated in a general way with advancing chronological age, but perhaps only in so far as the latter is also correlated with advancing maturity status. There is, in several of the subjects, a significant relation between the onset of the first menses and a more advanced hormonal picture. How close this relation is can only be revealed by blocs of observations spread over a longer period of time. It is difficult to decide whether cyclic significance should be attributed to the peaks and depressions which appear in the pre-menarchial records, and in the single post-menarchial one of the series (No. XIb, Figure 15). In view of the great irregularity of appearance of peaks, we are inclined to the view that the pituitary process is noncyclical at this time. In the adult, hormone peaks are frequently correlated with ovulation, but the weight of evidence seems to be against the pos- 
sibility of ovulation occurring or having occurred in most of the girls studied (8). Further, in only a few cases do these juvenile peaks of excretion approach in magnitude even the lowest peaks recorded for the normal menstrual cycle. Thus, it might be postulated that these amounts of hormone represent an output concerned primarily with the process of maturation of the gonads, and that the complete expression of the cycle must await ovarian maturation and the secretion of estrogens (androgens) and progesterone by the ovary. It is known that in childhood the urinary output of estrogens and androgens is low, and that the amounts of these hormones increase during adolescence $(2,3)$.

Until more records are obtained, it is not possible to assess the degree to which the results obtained with subjects $\mathrm{I}$ and XI represent actual pictures of late and very early maturation, respectively.

\section{CONCLUSIONS}

1. Measurements have been made of the daily urinary excretion of gonadotrophic hormone, by 12 girls between the ages of $4 \frac{1}{2}$ and 14 years, over periods of 30 consecutive days. On 4 of these girls, repeat observations were made after the lapse of a year.

2. In the urine of the youngest girls, either no hormone or only very small quantities could be detected. In preadolescent girls, hormone appeared more frequently, and in larger amounts. With increasing quantities, fluctuations in day by day amounts became evident, but these did not appear to be systematic or cyclic.

3. The pattern of gonadotrophic hormone output appeared to be related more closely to developmental status than to chronological age of the subjects.
4. Hormonal activity in girls was on a generally lower level than that recorded for the fully developed adult menstrual cycle. It is suggested that this activity is to be correlated with a preovulatory phase of sexual development.

We are deeply indebted to Drs. C. B. Gibson and L. D. Van Antwerp, State Tuberculosis Sanitorium, Meriden, Connecticut, and to Miss Caroline deF. Penniman and Miss Mary Anne Tuthill, Long Lane Farm, Middletown, Connecticut, for their generous cooperation in making available to us the subjects of this study. Our thanks are further due to Dr. C. S. Culotta of the Department of Pediatrics, Yale University School of Medicine, New Haven, Connecticut, for his help with physical study of the subjects.

\section{REFERENCES}

1. Greulich, W. W., et al., Somatic and endocrine studies of puberal and adolescent boys. Monographs of the. Society for Research in Child Development, Vol. VII, No. 3 (Serial No. 33). National Research Council, Washington, D. C., 1942.

2. Catchpole, H. R., and Greulich, W. W., Excretion of gonadotrophic hormone by prepuberal and adolescent girls. Am. J. Physiol., 1940, 129, 331.

3. Nathanson, I. T., Towne, L. E., and Aub, J. C., Normal excretion of sex hormones in childhood. Endocrinology, 1941, 28, 851.

4. Levin, L., Quantitative precipitation of the urinary gonadotropin of normal men and women. Endocrinology, 1941, 28, 378.

5. Werner, S. C., Quantitative study of the urinary excretion of hypophyseal gonadotropin, estrogen, and androgen of normal women. J. Clin. Invest., 1941, $20,21$.

6. von Haam, E., and Rothermich, N. O., Excretion of gonadotropic and estrogenic hormones in urine during normal menstrual cycle. Proc. Soc. Exper. Biol. and Med., 1940, 44, 369.

7. D'Amour, F. E., Further studies on hormone excretion during the menstrual cycle. Am. J. Obst. and Gynec., 1940, 40, 958.

8. Hartman, C. G., On the relative sterility of the adolescent organism. Science, 1931, 74, 226. 